\title{
Initial reactions to the Woman's Condom by potential user groups in Shanghai, China
}

\author{
Patricia S Coffey, ${ }^{1}$ Maggie Kilbourne-Brook, ${ }^{2}$ Wu Junqing, ${ }^{3}$ \\ Zhang Yufeng, ${ }^{4}$ Zhao Hongxin, ${ }^{5}$ Wen Bin, ${ }^{6}$ Li Na, $^{7}$ Zhao Rui, $^{8}$ Li Yuyan ${ }^{9}$
}

\begin{abstract}
${ }^{1}$ Senior Program Officer, PATH, Seattle, WA, USA

${ }^{2}$ Program Officer, PATH, Seattle, WA, USA

${ }^{3}$ Researcher, Shanghai Institute of Planned Parenthood Research, Shanghai, China

${ }^{4}$ Assistant Researcher, Shanghai Institute of Planned Parenthood Research, Shanghai, China ${ }^{5}$ International Company Staff, Shanghai Institute of Planned Parenthood Research, Shanghai, China

${ }^{6}$ Assistant Researcher, Shanghai Institute of Planned Parenthood Research, Shanghai, China

${ }^{7}$ Assistant Researcher, Shanghai Institute of Planned Parenthood Research, Shanghai, China

${ }^{8}$ Assistant Researcher, Shanghai Institute of Planned Parenthood Research, Shanghai, China

${ }^{9}$ Assistant Researcher, Shanghai Institute of Planned Parenthood Research, Shanghai, China
\end{abstract}

\section{Correspondence to}

Dr Patricia S Coffey, PATH,

PO Box 900922, Seattle,

WA 98107, USA

pcoffey@path.org

Received 1 September 2011

Accepted 24 May 2012

Published Online First

20 August 2012
To cite: Coffey PS, KilbourneBrook $M$, Junqing $W$, et al. Journal of Family Planning and Reproductive Health Care 2013;39:111-120.

\begin{abstract}
Background The Woman's Condom, a secondgeneration female condom, is currently being manufactured in China by the Shanghai Dahua Medical Apparatus Company. The manufacturer plans to launch the product in China.

Methods A survey and focus group discussions were conducted with 73 women and 57 men from nine potential user groups in the Shanghai area to explore, on the basis of visual inspection of the Woman's Condom and product information, their perceptions and attitudes toward the Woman's Condom and lubricant. The potential user groups were male and female university students, male and female collegeeducated young people, married women and men, migrant women and men, and women working in the entertainment industry.
\end{abstract}

Results Female condoms were a new concept for almost all study participants. Women (49\%) and men $(51 \%)$ reported that the Woman's Condom would make "some" or a "great" difference in their lives. Participants reported interest in using the Woman's Condom for sexually transmitted infection (STI) (50\%) or dual protection (43\%) rather than for pregnancy prevention alone (33\%). Findings highlighted comfort, partner approval and lubricant as possible concerns.

Conclusions Product introduction activities should be oriented toward the most likely early adopter groups (i.e. university students, collegeeducated young people, migrant women and women working in the entertainment industry). Lack of interest in using the new device by married women/men and migrant men may indicate that they do not perceive a need for a dual protection product since they are already using a contraceptive method and/or do not perceive themselves at risk of STIs.

\section{INTRODUCTION}

Millions of couples worldwide need protection against sexually transmitted

\section{KEY MESSAGE POINTS}

- Although female condoms are relatively unknown in China, we identified several user groups who expressed interest and willingness to purchase and use the Woman's Condom.

- Potential user groups expressed more interest in the Woman's Condom for sexually transmitted infection protection and dual protection, rather than for contraception alone.

- Men expressed more openness toward this new product than women, partly because it was perceived as more pleasurable than male condoms, which may be important for future promotion.

infections (STIs) and pregnancy. The World Health Organization estimates that 448 million cases of new, curable STIs occur annually. ${ }^{1}$ By 2007, women represented half of all HIV infections worldwide, with $80 \%$ of these occurring through sexual transmission. More than one in six married women and 1 in 13 never-married women aged 15-49 years have an unmet need for contraception. ${ }^{2}$ Although contraceptive prevalence among married women in China is high $(87 \%),{ }^{3}$ unmet need for family planning, especially among unmarried women, may be large as evidenced by the thirteen million abortions that occur annually primarily among unmarried women. ${ }^{4}$

Rates of infection with reportable STIs also have increased nearly four-fold from 1990 to 2002 (from 14 cases per 100 000 persons to 69 cases per 100000$).^{5}$

HIV is becoming an area of concern. By the end of 2009, approximately 740000 people in China were infected with HIV. 
In 2009, there were an estimated 48000 new HIV infections, with heterosexual transmission accounting for about $42 \%$ of these. ${ }^{6}$

The female condom is a class of product that protects against pregnancy $^{7}$ and STIs. ${ }^{8-11}$ The female condom provides female-initiated protection and is recommended for use especially when male condoms cannot be used. ${ }^{12}$ Although evidence is sparse, female condom use is also purported to improve communication between partners thereby enhancing women's empowerment. Female condoms have been marketed internationally since the mid-1990s; however, introduction into China has focused solely on clinical studies and a few pilot introduction studies with the first-generation female condom, FC1 ${ }^{\circledR}$ (Female Health Company). Several studies among married couples in the Shanghai area found the FC1 an acceptable contraceptive. In one study, couples reported that they found the female condom device acceptable for contraception with no difference in sensation from male condoms. ${ }^{13}$ In a second study, $55 \%$ of couples preferred female over male condoms. ${ }^{14}$ In a third study, couples reported similar acceptability for both FC1 and male condoms. ${ }^{15}$ The FC1 also was found to be similar to the male condom in safety and efficacy in a clinical study in Shanghai. ${ }^{16}$

Data from two intervention studies involving sex workers also show female condoms are acceptable and that with counselling and support, acceptability and use increases. A National Research Institute for Family Planning study in Ghuangdong province in 2002 showed that acceptability of female condoms increased from $60 \%$ to $94 \%$ in the intervention sites where women received an educational session and demonstration and discussion about the female condom. Discomfort and difficulties with insertion decreased dramatically after repeated practice. ${ }^{17}$ In 2004 , the Futures Group, in conjunction with the China UK HIV/AIDS project, distributed female condoms to sex workers in Sichuan and Yunnan provinces over a 3-month period as part of an intensive information, education and communication intervention. During that intervention, about $71 \%$ of surveyed sex workers indicated an interest in using female condoms. Clients reported that female condoms performed well in terms of sexual pleasure. The most significant barriers were high cost (10 RMB/approximately US $\$ 1.55$ per piece) and their aesthetic appearance. ${ }^{18}$

To date, female condom introduction activities in China have shown limited impact not only in terms of geographical coverage but also in the volume of female condoms distributed and sold. More in-depth analysis of social, cultural, contextual and individual factors underpinning female condom use is needed in China to assist with introduction efforts of a secondgeneration female condom product.

The Woman's Condom, a second-generation female condom product developed by $\mathrm{PATH}$, is currently being manufactured by the Shanghai Dahua Medical Apparatus Company. The Woman's Condom design was verified in user testing among 60 couples in three countries in $2004 .{ }^{19}$ More than $90 \%$ of couples in this design validation study, including nearly half of those who had no previous experience with female condoms, were satisfied with its performance for ease of use, stability, comfort and sensation. In 2005, the Woman's Condom was evaluated in a randomised crossover study at three sites in the USA comparing it to the FC1 female condom for functional performance, safety and acceptability. ${ }^{20}$ In that study, 75 couples evaluated both female condoms during four acts of intercourse at home. The Woman's Condom performed as well or better than the FC1 for functional performance, safety and acceptability. Among participants with a preference, the Woman's Condom was preferred over the FC1 by twice as many males and by 2.6 times as many females.

During 2007, the Woman's Condom was evaluated in a prospective, crossover study of product preference, acceptability and function of three female condom designs among 180 women in South Africa. The participants reported that the Woman's Condom was better than the Reddy $6 \AA$ in terms of feel; worse than both FC2 ${ }^{\circledR}$ and Reddy 6 as regards lubrication volume; and better than FC2 and Reddy 6 in terms of appearance, ease of use and overall fit. ${ }^{21}$

The Woman's Condom obtained market approval in China in late 2010. Since China will be the first market for introduction of the Woman's Condom, we conducted formative research to explore, on the basis of visual inspection of the Woman's Condom and product information, the perceptions, understanding and attitudes of potential target user groups in the Shanghai area regarding the Woman's Condom and lubricant and any potential barriers associated with its use.

\section{METHODS}

\section{Participants and study procedures}

The study was conducted between July 2009 and January 2010 in Shanghai, the largest city in China with over 20 million people. Participants for the focus group discussions were recruited from groups of women and men that have the potential to be Woman's Condom users in the future. User groups were selected by the research team after consultation with local reproductive health experts about groups that they thought would be the most likely potential users of the device. User groups reflected a range of ages, occupations and educational backgrounds. All participants were selected for their eligibility in one of nine user groups defined in Table 1. In addition, participants (1) identified they were sexually active, (2) were able and willing to provide written informed consent and (3) agreed to talk willingly about sensitive topics. 
Table 1 Focus group discussion user groups

\begin{tabular}{|c|c|}
\hline Potential user groups & Inclusion criteria \\
\hline Male university students & Males aged 18-30 years attending medical or non-medical university \\
\hline Female university students & Females aged 18-30 years attending medical or non-medical university \\
\hline $\begin{array}{l}\text { Women working in entertainment } \\
\text { industry }\end{array}$ & Women aged 18-45 years who work at karaoke bars located in downtown Shanghai \\
\hline Married women & Women aged $20-45$ years residing in urban Shanghai who are married \\
\hline Married men & Men aged 20-45 years residing in urban Shanghai who are married \\
\hline Migrant women & $\begin{array}{l}\text { Married women aged } 20-45 \text { years working in rural areas (Ming Hang, Jiading and Hongqiao) who were not born in } \\
\text { their current area of employment and who have lived in their current location for at least } 6 \text { months }\end{array}$ \\
\hline Migrant men & $\begin{array}{l}\text { Married men aged 22-45 years working in Ming Hang, Jiading and Hongqiao who were not born in their current } \\
\text { area of employment and who have lived in their current location for at least } 6 \text { months }\end{array}$ \\
\hline College-educated young women & $\begin{array}{l}\text { Women aged } 22-35 \text { years who have attended some college or university and who are currently working at } \\
\text { companies based in Shanghai }\end{array}$ \\
\hline College-educated young men & $\begin{array}{l}\text { Men aged 22-35 years who have attended some college or university and who are currently working at companies } \\
\text { based in Shanghai }\end{array}$ \\
\hline
\end{tabular}

Study participants were recruited using various methods. Male and female university students were recruited via recruitment posters placed around the university campus. Women working in the entertainment industry were contacted through the 'Mommy' to gain permission to participate. The 'Mommy' is a woman who manages a sex worker establishment. Married and migrant women and men were recruited in collaboration with the District Family Planning Committee and workplace or community leaders. College-educated young women and men were contacted through the family planning co-ordinator at each workplace. All potential study participants that met eligibility requirements agreed to be enrolled in the study.

Researchers from the Shanghai Institute of Planned Parenthood Research (SIPPR) conducted two focus group discussions with each user group. Researchers were trained about how to describe and demonstrate the Woman's Condom and lubricant, qualitative research emphasising focus group discussion and free listing methods, the elements of informed consent and pretesting of data collection forms and recruitment materials such as phone scripts that were used to respond to university students when they called to inquire about the study.

The study was implemented by trained researchers/ facilitators comprising graduate students in public health at SIPPR using a standard discussion guideline. The guides used open-ended questions to elicit a full spectrum of data about the (1) need for protection and perception of risk of STIs and unintended pregnancy; (2) common terms used to describe sex, sexual pleasure, condoms and male and female genitalia; (3) acceptability of the Woman's Condom; (4) experiences, attitudes and beliefs about vaginal lubricants and about inserting other products or medicine into the vagina; (5) packaging concepts; (6) possible use scenarios and barriers to use and (7) preferred sources for access and/or distribution (not all aspects of these data are reported here). Free listing exercises were used to elicit data about sexual and reproductive health terms commonly used and methods that reduce risk of unintended pregnancy and/or STIs.

The focus group discussions were conducted in private venues appropriate for the specific user group. Discussions with university students were held in a private meeting room on campus. Discussions with women working in the entertainment industry were held in a private room of a tea house near to their working establishment. Married women met in a private room at the Family Planning Committee office whereas married men, migrant women and men and college-educated women and men met in private meeting rooms at the factory or workplace.

Mixed research methods were used to triangulate the data gathered during the focus group discussions and self-administered surveys. Analysing both qualitative and quantitative data together allow for a more complete picture of the situation to form than if only one type of data were collected. Following informed consent and prior to the focus group discussion, participants completed a self-administered demographic questionnaire. After the focus group discussion, participants were asked to complete a self-administered questionnaire about willingness to pay for and use the Woman's Condom.

\section{Study device}

Although study participants did not use the Woman's Condom before or during the focus group discussion, each participant received a sample Woman's Condom and lubricant to handle and explore. The facilitator described the product and demonstrated insertion and removal using her hands as a model. This provided the reference point for respondent answers about the product.

The Woman's Condom consists of a very thin, pliable plastic pouch that easily conforms to the shape of the vagina. It is 9 inches $( \pm 0.1$ inch) long and has 
a flexible, soft outer ring that is designed to hug the external genitalia. Several design innovations differentiate it from other female condom products, notably the hydrophilic foam shapes that serve to hold the condom pouch within the vagina during use and the insertion capsule which holds the condom pouch compactly allowing for easier insertion than other designs.

The condom pouch is produced from polyurethane film; the base resin used in its production is qualified to United States Pharmacopeia Class 6. The external ring is made from thermoplastic polyurethane. The foam shapes are made from hydrophilic urethane foam and the insertion capsule is made of dissolvable polyvinyl alcohol. The lubricant used with the Woman's Condom is water-soluble and nonspermicidal. Figure 1 illustrates the Woman's Condom feature set.

\section{Data management and analysis}

All data were collected in Mandarin Chinese and handled with procedures to protect participant anonymity. All data were treated as confidential and only study researchers had access to the study databases. Prior to the start of the focus group discussions, participants were reminded that they should not share personal stories expressed in the group outside of the meeting.

Quantitative data from the self-administered questionnaires were double entered in EpiData ${ }^{\mathrm{TM}}$ (EpiData Association, Odense, Denmark). Discrepancies were checked against the original questionnaires and

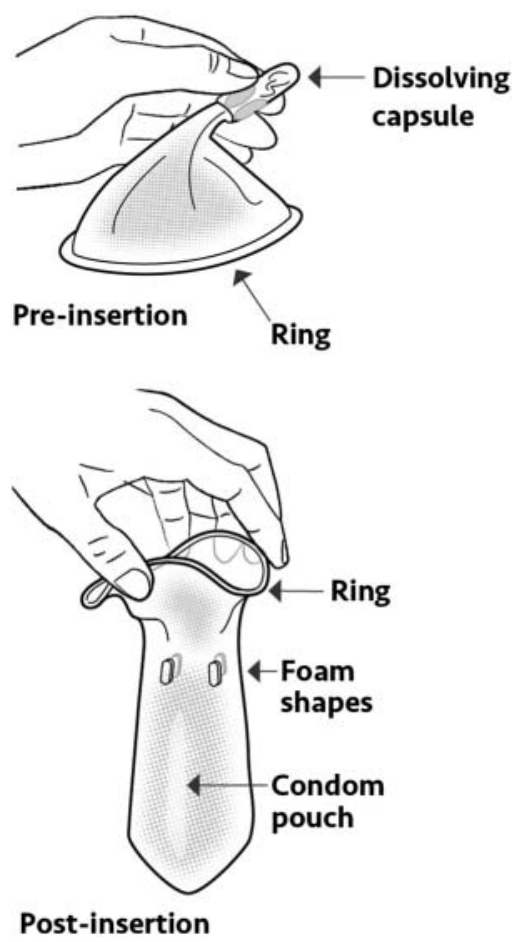

Figure 1 Illustration showing a Woman's Condom. corrected. Cleaned data were transferred into statistical analysis software SAS 9.1.3 ${ }^{\mathrm{TM}}$ (SAS Institute Inc., Cary, NC, USA) for analysis. Data were summarised using frequency tables for categorical variables.

Each focus group discussion was tape recorded and transcribed verbatim in Mandarin. A note-taker created a written document that was used to supplement the transcripts. Multiple members of the research team read all focus group discussion transcripts for comprehension and quality control. Qualitative data were coded, managed and analysed using NVivo 8.0 $0^{\mathrm{TM}}$ (QSR International, Doncaster, Australia). The coding scheme was generated from the areas of inquiry and relevant literature. At least two different coders independently reviewed each transcript and resolved any differences by consensus. Investigators followed standard content analysis to summarise codes, accounting for and interpreting major themes and relationships with other codes and themes.

\section{RESULTS}

The study was conducted between July 2009 and January 2010 in Shanghai, China. Results are drawn from 18 focus group discussions implemented among nine different potential target audiences. The 130 participants (57 men and 73 women) ranged in age from 20 to 53 years. Nearly all the participants reported being of Han ethnicity. Two-thirds (65\%) of the participants reported completing college/university or higher (primarily participants in the university student or college-educated young people groups). Over half of the participants reported currently using a contraceptive method. Migrant women, male university students, married women and women in the entertainment industry reported the highest rates of contraceptive use $(100 \%, 81 \%, 73 \%$ and $53 \%$, respectively). Female university students and college-educated women had much lower rates of contraceptive use (6\% and 33\%, respectively). Male condoms were the most commonly reported contraceptive method followed by the intrauterine device (IUD). Current condom use was reported primarily by male participants (university students, college-educated young men and married urban men). IUD use was reported primarily by migrant women, married urban women and, to a lesser extent, women in the entertainment industry. All but two participants assessed themselves as having no risk for STIs. Demographic information is summarised in Table 2.

\section{Perceived risk of unintended pregnancy and STIs}

The majority of participants from all groups stated that premarital and extramarital sex has become so common in Shanghai that the risk for people in their community for unintended pregnancy and STIs has increased. University students and college-educated young people stated this risk clearly. "Many of my 
Table 2 Participant characteristics by number and potential user groups $(n=130)$

\begin{tabular}{|c|c|c|c|c|c|c|c|c|c|}
\hline \multirow[b]{2}{*}{ Characteristic } & \multicolumn{2}{|c|}{$\begin{array}{l}\text { University students } \\
(n=32)\end{array}$} & \multicolumn{2}{|c|}{$\begin{array}{l}\text { College-educated young } \\
\text { people }(n=28)\end{array}$} & \multicolumn{2}{|c|}{$\begin{array}{l}\text { Migrant workers } \\
(n=27)\end{array}$} & \multicolumn{2}{|c|}{$\begin{array}{l}\text { Married urban Shanghai } \\
\text { residents }(n=30)\end{array}$} & \multirow{2}{*}{$\begin{array}{l}\text { Women working in } \\
\text { entertainment } \\
\text { industry }(n=13)\end{array}$} \\
\hline & $\begin{array}{l}\text { Female } \\
(n=16)\end{array}$ & $\begin{array}{l}\text { Male } \\
(n=16)\end{array}$ & $\begin{array}{l}\text { Female } \\
(n=15)\end{array}$ & $\begin{array}{l}\text { Male } \\
(n=13)\end{array}$ & $\begin{array}{l}\text { Female } \\
(n=14)\end{array}$ & $\begin{array}{l}\text { Male } \\
(n=13)\end{array}$ & $\begin{array}{l}\text { Female } \\
(n=15)\end{array}$ & $\begin{array}{l}\text { Male } \\
(n=15)\end{array}$ & \\
\hline Age in years, median (range) & $22.7(20-27)$ & $26.1(22-30)$ & $27.1(24-32)$ & $27.4 p(23-31)$ & $40.2(35-45)$ & $33.9(23-44)$ & $37.87(26-53)$ & $33.9(24-45)$ & $26.5(21-40)$ \\
\hline \multicolumn{10}{|l|}{ Ethnicity* } \\
\hline Han & 16 & 15 & 14 & 13 & 14 & 13 & 15 & 14 & 13 \\
\hline Other & 0 & 1 & 1 & 0 & 0 & 0 & 0 & 0 & 0 \\
\hline \multicolumn{10}{|l|}{ Educational level† } \\
\hline Primary school or below & 0 & 0 & 0 & 0 & 5 & 1 & 0 & 0 & 0 \\
\hline Junior school & 0 & 0 & 0 & 0 & 5 & 8 & 3 & 1 & 3 \\
\hline High/technical training/school & 0 & 0 & 0 & 0 & 3 & 2 & 5 & 4 & 5 \\
\hline College/university & 5 & 6 & 3 & 4 & 1 & 1 & 7 & 9 & 5 \\
\hline Master and above & 11 & 10 & 12 & 9 & 0 & 0 & 0 & 0 & 0 \\
\hline \multicolumn{10}{|l|}{ Contraceptive method use } \\
\hline Current use any method $\ddagger$ & 1 & 13 & 5 & 8 & 14 & 7 & 11 & 9 & 7 \\
\hline IUD & 0 & 0 & 0 & 0 & 10 & 2 & 5 & 1 & 2 \\
\hline Male condoms & 1 & 12 & 3 & 8 & 1 & 5 & 6 & 8 & 4 \\
\hline Tubal ligation & 0 & 0 & 0 & 0 & 1 & 0 & 0 & 0 & 1 \\
\hline Oral contraceptives & 0 & 1 & 1 & 0 & 0 & 0 & 0 & 0 & 0 \\
\hline Emergency contraception & 0 & 0 & 1 & 0 & 0 & 0 & 0 & 0 & 0 \\
\hline Rhythm method & 0 & 0 & 0 & 0 & 1 & 0 & 0 & 0 & 0 \\
\hline Ever use male condom & 2 & 13 & 5 & 11 & 3 & 6 & 8 & 12 & 4 \\
\hline \multicolumn{10}{|l|}{ STI self-screening risk (scale 0-10) } \\
\hline 0 & 16 & 16 & 15 & 13 & 13 & 13 & 15 & 15 & 12 \\
\hline 1 & 0 & 0 & 0 & 0 & 1 & 0 & 0 & 0 & 0 \\
\hline 3 & 0 & 0 & 0 & 0 & 0 & 0 & 0 & 0 & 1 \\
\hline
\end{tabular}

*Missing data: one for male married urban Shanghai residents.

† Missing data: one for male migrant workers and male married urban Shanghai residents.

¥Missing data: one for specific method breakdown for female migrant workers.

IUD, intrauterine device; STI, sexually transmitted infection. 
classmates now have girlfriends and they often had sex without any contraception methods" (male university student). Conversely, participants in other groups, especially married women and men, did not feel at risk of unintended pregnancy. One married woman explained: "That is impossible. We all have children. Nearly all of us have used the IUD. That is absolutely impossible to be pregnant!"

Participants from groups of married and migrant men, college-educated young men and women, and female university students believed that some people around them were at risk of HIV/AIDS or STIs. In all groups except migrant women, participants acknowledged STI risk through comments such as: "Absolutely many people are at risk of RTI [reproductive tract infections])/STDs in the modern world of Shanghai". However, participants did not perceive they were personally at risk of HIV/AIDS or STIs although they felt that other people might be. One college-educated young woman said: "I am totally not at risk. But I know many people may have the risks of STI or AIDS".

As part of the free listing exercise, participants identified methods that reduce risk of unintended pregnancy and methods that reduce the risk of STIs. In all groups except migrant women, condoms were identified on both lists. Migrant women identified the IUD, oral contraceptives, abstinence and rhythm as methods to reduce unintended pregnancy and "being faithful" as the only way to reduce STI risk.

\section{Current perceptions of male condoms and their use}

Since female condoms are not widely known in the community, participants were asked how male condoms currently are perceived among populations in Shanghai, what the word 'condom' meant to them, and their feelings when they heard the word 'condom'. Most participants (both men and women) believed they felt "secure" when they heard 'condom', probably because the Chinese translation "An Quan Tao" means "a secure instrument". Some participants, however, stated jokingly that the condom is not safe. One married man asserted: "Unlike its name, I don't think condom is absolutely safe. Contraceptive failure happens frequently".

University students and college-educated young people expressed an open attitude toward condoms more often than married women or men. Participants from these groups said that the word 'condom' is common in discussions and that they would hear and use it with ease. However, a few of the female university students and younger migrant men said that they would be shy to hear the word 'condom' in a conversation. Other female students and migrant men were curious, as they had never used it. A migrant man stated: "Condom - the name sounds good! I have not used it before and want to have a try".
Married, college-educated and migrant men all agreed that contraception is the primary reason for condom use. These same groups, together with college-educated young women, recognised HIV/STI prevention as being another role for condoms. Male university students, college-educated young men and married women identified ease of use as a main reason for using condoms. Male university students appeared more familiar with condoms than other groups. They cited additional reasons for using condoms including fewer side effects and viewed them as practical, economical and trusted. As one student explained: "The condoms were advertised for many years. We believe that they are safe and reliable".

Across all groups, male participants expressed greater interest and willingness to use a condom than women. Women's lack of interest in condom use appeared to be related to their use and related satisfaction of other contraceptive methods, primarily IUDs. One migrant woman said: "IUD seems more convenient for us. But for some people who face risks or with side effects, they truly need to use condom".

\section{Potential acceptability of the Woman's Condom and lubricant}

Focus group participants brainstormed words to use when introducing the Woman's Condom to their friends. These included words such as interesting, safe, comfortable, funny, thin, sex product, for women, another choice, dual protection, fashion, female-dominated, change your flavour, sexual equality and have a try. These words show the wide range of attitudes held by these potential user groups toward the Woman's Condom.

Participants also shared words that reflected their feeling when they first viewed the Woman's Condom. Women shared words related to product function such as inconvenient, complicated and weird. While men acknowledged those product characteristics, they also focused on more positive images such as fresh, mystical, brilliant and exquisite.

The Woman's Condom is manufactured as a nonlubricated device. The user is instructed to apply lubricant to the inside of the pouch as part of product insertion. Participants were asked whether lubricants are commonly available and used in China and about attitudes regarding applying lubricant to this product. Only about one-quarter of participants had heard of sexual lubricants. They said lubricant is not commonly used during sex and/or mostly used by older people. "When someone starts to use lubricant, the first impression is the woman is getting older" (college-educated young woman). Some female participants also indicated that use of a lubricant product may not be culturally acceptable. "It's strange and new. I am not sure if Chinese people would accept this product" (married woman). 
Table 3 Potential acceptability of the Woman's Condom $(n=130)$

\begin{tabular}{lcc}
\hline Questions about acceptability & Women (\%) $(\boldsymbol{n = 7 3 )}$ & Men (\%) $(\boldsymbol{n = 5 7 )}$ \\
\hline If the Woman's Condom was available to you now, how big a difference would it make in your life? ${ }^{*} \dagger$ & $9(12)$ & $5(9)$ \\
It could make a great difference & $26(37)$ & $24(42)$ \\
It could make some difference & $16(23)$ & $18(32)$ \\
It would not make a difference at all & $20(28)$ & $10(18)$ \\
It would make no difference for me personally but it may affect other couples & $52(71)$ & $34(60)$ \\
What are your concerns about using the Woman's Condom? & $34(47)$ & $29(51)$ \\
Difficult to insert the condom properly & $60(82)$ & $42(74)$ \\
Difficult to remove properly & $51(70)$ & $33(58)$ \\
Might feel uncomfortable to wear the condom during sex & $50(68)$ & $49(86)$ \\
May make sex less enjoyable for me & $53(73)$ & $37(65)$ \\
My partner may not approve of the condom &
\end{tabular}

${ }^{*}$ Missing two data points for women $(n=71)$.

tNB. Respondents did not perceive themselves to be at risk of sexually transmitted infection or unwanted pregnancy at the time of the survey.

Most participants felt the lubricant was inconvenient, and women were uncomfortable having to apply the lubricant with their finger. Participants preferred having the condom be pre-lubricated and suggested a range of novel methods for applying lubricant to the condom so the woman does not have to touch herself.

About half the women (49\%) and men (51\%) reported on the self-administered questionnaire that the Woman's Condom would make "some" difference or a "great difference" in their lives (Table 3). Many participants were willing to try the Woman's Condom, and they also expressed a variety of concerns. The most common concern expressed by women was that the device might feel uncomfortable during sex or that it would make sex less enjoyable for their partner. "He may be frightened! Never seen this strange thing before!" (married woman). The most common concern for men was that their partner might not approve of the device or that it would be uncomfortable. Almost two-thirds (61.5\%) of all participants stated that they would not be embarrassed to purchase a Woman's Condom. However, they preferred that the price be less than 5 Yuan (US\$0.67) for one item.

\section{Motivation to use the Woman's Condom}

Overall, participants were more interested in using the Woman's Condom for STI (50\%) or dual protection (43\%) than for pregnancy prevention alone (33\%). Male university students, migrant women and women working in the entertainment industry were interested in using the woman's condom for dual protection. One male university student stated: "I think the material is better than the male condom. It may be useful in HIV prevention".

Male university students also saw the device as a pleasure-enhancing product that may be comfortable for men. The majority of college-educated young men were interested in the device solely for STI protection.
Participants from the other potential user groups who expressed interest in using the Woman's Condom (female university students, college-educated young women, migrant men and male and female married urban Shanghai residents) were not clear about their motivation for interest.

Participants from five of the user groups (female and male university students, college-educated young women and men and women working in the entertainment industry) saw the potential for the Woman's Condom to be initiated by women as a positive attribute of the device. One college-educated young man said: "Women can decide independently whether they would choose contraception or not. This is its greatest strength". A woman working in the entertainment industry noted: "We can use it by ourselves. That's reassuring".

\section{DISCUSSION}

Results from this initial investigation into the hypothetical acceptability of the Woman's Condom among potential user groups in China highlights perceptions and attitudes regarding the Woman's Condom and lubricant and potential barriers associated with its use. Although female condoms were a new concept for almost all study participants, study findings show interest among several potential user groups for this new female condom product both for STI protection and as a dual protection method. Overall, male university students, college-educated young men, migrant women and women working in the entertainment industry were most interested in the dual protection aspects of the device, whereas female university students and college-educated young women were most interested in the device for pregnancy prevention. Generally, male participants appeared to be more intrigued by the device than female participants. Of particular note was the interest in the device by women working in the entertainment industry, both 
because of the ability of the device to provide dual protection and because it was female-initiated. This interest in, and willingness to use, the Woman's Condom by women working in the entertainment industry is consistent with reports of their interest and use of other female condom products. ${ }^{22-24}$

The study participants did not perceive themselves to be at risk of either unintended pregnancy or STI/ HIV. China's HIV prevalence overall is quite low $(0.057 \%)$ and previously was localised among highrisk groups (injecting drug users, former plasma donors and men who have sex with men), and only recently has begun to spread more generally. It is not surprising that the participants in this study did not perceive themselves to be at risk from HIV given that we did not include those high-risk groups. The absence of perception of personal risk for unintended pregnancy, especially for married women using IUDs, could be due to the success of the national family planning programme in reaching married women and China's historical reliance on long-term methods.

Nevertheless, data from sexual behaviour surveys document that STI risk exists in many of the potential user groups included in our study. For example, a study among migrant men in construction sites, markets and factories in Shanghai found that among 986 sexually active men, $14 \%$ had had more than one sexual partner in their lifetime, $31 \%$ premarital sex and $78 \%$ had never used condoms. ${ }^{25}$ In a study of 4769 female university students in Wuhan, an area west of Shanghai, $863(18.1 \%)$ women reported ever having sexual intercourse and $5.3 \%$ reported having multiple sex partners $(29.3 \%$ of all women having sexual intercourse). ${ }^{26}$ In a study of 22493 undergraduate students in two universities in Ningbo, $17.6 \%$ of males and $8.6 \%$ of females reported being sexually active and $35 \%$ of sexually active students in both genders reported that condoms were rarely/never used in the previous year. Pregnancy and induced abortion had each been experienced by about $10 \%$ of sexually active female students and the female partners of male students, and about $1.5 \%$ of sexually active students of both genders reported being diagnosed with an STI. ${ }^{27}$

Although the participants in our study did not feel that they were personally at risk of STI or unintended pregnancy, they acknowledged the risk of sexual behaviour for their peers. And although many may engage in high-risk behaviour, they do not always perceive themselves to be at risk of STIs as has been documented in the case of migrant men. ${ }^{28}$ Introducing a new female condom design such as the Woman's Condom may help to fill the unmet need for contraception in these groups.

The perceived lack of risk for unintended pregnancy on the part of female university students and college-educated young women may be linked to infrequent or unplanned sex, easy access to abortion, male partner condom use, and/or lack of knowledge about the risk. Data from a 2002 survey among unmarried out-of-school youth aged 16-24 years from a suburb of Shanghai showed similar behavioural intention related to unintended pregnancy. Most of the 1304 youths in the study had a favourable attitude toward premarital sex yet only one-fifth of sexually active youths had always used a contraceptive method and one-quarter had experienced pregnancy. Reasons for non-use of contraception included infrequent or unexpected sex, too shy to obtain contraceptives, lack of knowledge about contraceptives and dislike of how contraceptives influence sexual pleasure or mood. ${ }^{29}$

Interestingly, men (particularly male university students and college-educated men) expressed more openness toward this type of product than their female counterparts. This attitude also is reflected in the more positive and imaginative words men used to describe their feelings about this product. This finding could be important as future promotional strategies are developed for this product.

Generally, female participants were more sceptical about using the Woman's Condom than male participants. Women were concerned about the fit and feel of the device both for themselves and their partners. It is possible that college-educated woman and university students were less interested in the Woman's Condom because of their lack of familiarity and experience with female condoms and also since women are the ones who place it in their bodies. Previous studies during the Woman's Condom product development found that women are more positive about the device after using it and understanding not only how it works but also how it feels during sex (P. Coffey, unpublished data, 2005).

Few participants expressed knowledge or interest in use of lubricants, even though a large range of sexual lubricants are commercially available in grocery stores and sex shops in Shanghai as well as through online retail outlets. Some, although probably not all, of the participants in the focus group discussions have access to these distribution points. Lack of interest in lubricants among the potential user groups may be at odds with the need to use lubricant with the device. It is also possible that sexual lubricant is still considered a sensitive topic among these user groups and therefore too embarrassing to discuss. Clearly, unwillingness to discuss and/or use sexual lubricants may have a negative impact on user uptake of the Woman's Condom.

Lack of interest in using the new device by married women/men and migrant men may indicate that they do not perceive a need for a dual protection product since they are already using a contraceptive method and/or do not perceive themselves at risk of STIs. These results demonstrate that product introduction activities should be oriented toward the most likely early adopter groups (i.e. university students, college-educated young people, migrant women and 
women working in the entertainment industry) and that male partners could be an important entry point for engaging female university students and college-educated women.

A limitation of this study is that female condoms are relatively unknown in China, and most participants had never seen a female condom. Since participants did not use the Woman's Condom as part of this study, their responses are based on hypothetical assumptions that may differ from their experience after product use. This is an exploratory study and, as such, the findings cannot be generalised to the population but rather provide localised context for efforts related to the introduction of this contraceptive method in China.

Acknowledgements The authors are indebted to the study participants for sharing their views and perspectives with the researchers. The authors thank the research team for their hard work and commitment toward evaluating this new product. They also want to thank Clarissa Lord Brundage and Laura East for manuscript preparation. The manuscript content is the responsibility of the authors and does not necessarily reflect the views of USAID, the US Government or other donors.

Funding This study received funding from the Bill and Melinda Gates Foundation. Support for this study was made possible by the generous support of the American people through the United States Agency for International Development (USAID) under the terms of the HealthTech IV Cooperative Agreement \#GPH-A-00-01-00005-00 and other donors.

\section{Competing interests None.}

Ethics approval This study was approved both by the PATH Research Ethics Committee and the Ethics Committee of SIPPR.

Provenance and peer review Not commissioned; externally peer reviewed.

\section{REFERENCES}

1 World Health Organization (WHO). Sexually Transmitted Infections [Fact Sheet]. Geneva, Switzerland: WHO; August 2011. http://www.who.int/mediacentre/factsheets/fs110/en/ [accessed 14 March 2012].

2 Levine R, Langer A, Birdsall N, et al. Contraception. In: Jamison DT, Breman JG, Measham AR, et al. (eds). Disease Control Priorities in Developing Countries (2nd edn). Washington, DC: World Bank, 2006;1075-1090.

3 United Nations Department of Economic and Social Affairs Population Division (UNDESA). World Contraceptive Use 2009. POP/DB/CP/Rev2009. New York, NY: UNDESA, 2009.

$4 \mathrm{CNN}$. China has more than 13 million abortions a year. 30 July 2009. http://www.cnn.com/2009/WORLD/asiapcf/07/30/ china.abortions.millions/index.html [accessed 14 March 2012].

5 Remez L. STD rates soar in China; three in four new cases are among the unmarried. Int Fam Plan Perspect 2000;26:141-142.
6 Chinese Ministry of Health, UNAIDS, WHO. 2009 Estimates for the HIV/AIDS Epidemic in China. Beijing, China: National Center for AIDS/STD Control, Prevention, China CDC; 2010. http://www.unaids.org.cn/download/2009\%20China $\%$ 20Estimation\%20Report-En.pdf [accessed 14 March 2012].

7 Trussell J, Sturgen K, Strickler J, et al. Comparative contraceptive efficacy of the female condom and other barrier methods. Fam Plann Perspect 1994;26:66-72.

8 Soper DE, Shoupe D, Shangold GA, et al. Prevention of vaginal trichomoniasis by compliant use of the female condom. Sex Transm Dis 1993;20:137-139.

9 Fontanet AL, Saba J, Chandelying V, et al. Protection against sexually transmitted diseases by granting sex workers in Thailand the choice of using the male or female condom: results from a randomized controlled trial. AIDS 1998;12:1851-1859.

10 French PP, Latka M, Gollub EL, et al. Use-effectiveness of the female versus male condom in preventing sexually transmitted disease in women. Sex Transm Dis 2003;30:433-439.

11 Hoke TH, Feldblum PJ, Van Damme K, et al. Temporal trends in sexually transmitted infection prevalence and condom use following introduction of the female condom to Madagascar sex workers. Int J STD AIDS 2007;18:461-466.

12 World Health Organization Department of Reproductive Health, Research (WHO/RHR) and Johns Hopkins Bloomberg School of Public Health/Center for Communication Programs (CCP), INFO Project. Family Planning: A Global Handbook for Providers. Baltimore, MD and Geneva, Switzerland: CCP and WHO, 2007.

$13 \mathrm{Xu}$ J, Wu Y, Gao QJ, et al. Sino-Female condom: a study of its user acceptability. Reprod Contraception 1997;17: 235-240.

14 Zhou X, Liuqi Z, Yu W. A female condom (Reality $\left.{ }^{\circledR}\right)$ : study of its user acceptability. Chin J Fam Plan 2000;1:18-20.

15 Jiang BF, Guo XY, Fu P, et al. Comparative study on acceptability of female and male condom. Reprod Contracept 2004;24:99-102.

$16 \mathrm{Xu} \mathrm{J}, \mathrm{Wu}$ Y, Cao Q. Contraceptive efficacy of Sino-female condom: comparison with condom. [in Chinese]. Zhonghua Fu Chan Ke Za Zhi 1999;34:33-35.

17 Yimin C, Zhaohui L, Xianmi W, et al. Introductory study on female condom use among sex workers in China. Contraception 2002;66:179-185.

18 China/UK HIV/AIDS Prevention and Care Project. Manual of Condom Social Marketing. Shanghai, China: China Health Publishing House, 2006.

19 Coffey PS, Kilbourne-Brook M, Austin G, et al. Short-term acceptability of the PATH Woman's Condom among couples at three sites. Contraception 2006;73:588-593.

20 Schwartz JL, Barnhart K, Creinin MD, et al. Comparative crossover study of the PATH Woman's Condom and the FC Female Condom. Contraception 2008;78:465-473.

21 Joanis C, Beksinska M, Hart C, et al. Three new female condoms: which do South-African women prefer? Contraception 2011;83:248-254.

22 Liao S, Weeks MR, Wang Y, et al. Female condom use in the rural sex industry in China: analysis of users and non-users at post-intervention surveys. AIDS Care 2011;23(Suppl. 1): 66-74.

23 Liao S, Weeks MR, Wang Y, et al. Inclusion of the female condom in a male condom-only intervention in the sex industry in China: a cross-sectional analysis of pre- and post-intervention surveys in three study sites. Public Health $2011 ; 125: 283-292$. 
24 Weeks MM, Abbott M, Liao S, et al. Opportunities for woman-initiated HIV prevention methods among female sex workers in southern China. J Sex Res 2007;44: 190-201.

25 He N, Detels R, Chen Z, et al. Sexual behavior among employed male rural migrants in Shanghai, China. AIDS Educ Prev 2006;18:176-186.

26 Yan $\mathrm{H}$, Chen W, Wu H, et al. Multiple sex partner behavior in female undergraduate students in China: a multi-campus survey. BMC Public Health 2009;9:305.
27 Ma Q, Ono-Kihara M, Cong L, et al. Sexual behavior and awareness of Chinese university students in transition with implied risk of sexually transmitted diseases and HIV infection: a cross-sectional study. BMC Public Health 2006;6:232.

28 Rou K, Sullivan SG, Liu P, et al. Scaling up prevention programmes to reduce the sexual transmission of HIV in China. Int J Epidemiol 2010;39(Suppl. 2):ii38-ii46.

29 Wang B, Li X, Stanton B, et al. Sexual attitudes, pattern of communication, and sexual behavior among unmarried out-of-school youth in China. BMC Public Health 2007;7:189.

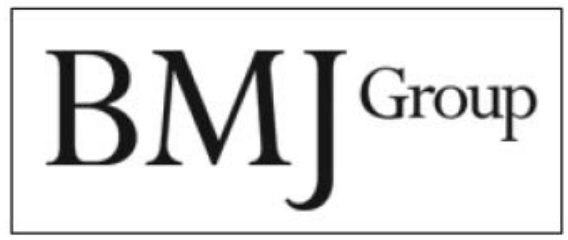

\section{VACANCY - SOCIAL MEDIA EDITOR}

Journal of Family Planning and Reproductive Health Care (JFPRHC), published by the BMJ Group on behalf of the Faculty of Sexual and Reproductive Health Care in the UK, has an exciting vacancy for an enthusiastic Social Media Editor to drive the journal's web presence worldwide.

JFPRHC is a peer reviewed journal that aims to improve reproductive and sexual health nationally and internationally, and publishes high quality research and information relevant to clinical care, service delivery, training and education in the field of contraception and reproductive/sexual health. More information can be found at jfprhc.bmj.com.

JFPRHC already has a strong readership and offers online features such as a blog, podcasts, Facebook and Twitter. This new post has been created to assist the editorial team in improving the journal's interactivity and web presence via these and other social media, by promoting the journal's content as well as helping its core readership to stay up to date with news and developments in the field.

You should be educated to degree level with knowledge of the journal's subject area. Some experience of science communication and/or web content management systems such as Twitter, Facebook and WordPress would be preferred, but the main criteria for the successful applicant will be enthusiasm for the subject area, creativity, and an interest in using new technologies to disseminate scientific research. The role would be ideally suited to a junior researcher or practising clinician.

The Social Media Editor will report directly to the journal's Editor-in-Chief, and will be expected to participate in the journal's regular editorial meetings. This is an unpaid position, but training and support will be provided by the BMJ Group's digital communication team.

To apply, please send your CV and covering letter to Lindsey Fountain, Journals Manager at the BMJ Group, at Ifountain@bmigroup.com. 